\title{
Simultaneous analysis of free amino acids and biogenic amines in honey and wine samples using in loop orthophthalaldeyde derivatization procedure
}

\author{
V. Pereira, M. Pontes, J.S. Câmara, J.C. Marques* \\ Centro de Química da Madeira, Departamento de Química da Universidade da Madeira, \\ Campus Universitário da Penteada, 9000-390 Funchal, Portugal
}

Available online 15 December 2007

\begin{abstract}
This work presents a RP-HPLC method for the simultaneous quantification of free amino acids and biogenic amines in liquid food matrices and the results of the application to honey and wine samples obtained from different production processes and geographic origins. The developed methodology is based on a pre-column derivatization with $o$-phthaldialdehyde carried out in the sample injection loop. The compounds were separated in a Nova-Pack RP-C ${ }_{18}$ column $(150 \mathrm{~mm} \times 3.9 \mathrm{~mm}, 4 \mu \mathrm{m})$ at $35^{\circ} \mathrm{C}$. The mobile phase used was a mixture of phase A: $10 \mathrm{mM}$ sodium phosphate buffer ( $\mathrm{pH} 7.3$ ), methanol and tetrahydrofuran (91:8:1); and phase B: methanol and phosphate buffer (80:20), with a flow rate of $1.0 \mathrm{ml} / \mathrm{min}$. Fluorescence detection was used at an excitation wavelength of $335 \mathrm{~nm}$ and an emission wavelength of $440 \mathrm{~nm}$. The separation and quantification of 19 amino acids and 6 amines was carried out in a single run as their OPA/MCE derivatives elute within 80 min, ensuring a reproducible quantification. The method showed to be adequate for the purpose, with an average RSD of $2 \%$ for the different amino acids; detection limits varying between $0.71 \mathrm{mg} / \mathrm{l}$ (Asn) and $8.26 \mathrm{mg} / \mathrm{l}$ (Lys) and recovery rates between $63.0 \%$ (Cad) and $98.0 \%$ (Asp). The amino acids present at the highest concentration in honey and wine samples were phenylalanine and arginine, respectively. Only residual levels of biogenic amines were detected in the analysed samples.
\end{abstract}

(C) 2007 Elsevier B.V. All rights reserved.

Keywords: Amino acids; Biogenic amines; Honey; Wine; OPA; RP-HPLC

\section{Introduction}

Amino acids and biogenic amines co-exist in biological and food matrices and participate in several transformation processes [1]. Amino acids play a central role as building blocks of proteins and as intermediates in the metabolism. They represent an important part of the human body as proteins are found in muscles, tendons, organs, glands, nails and hair, and promote growth, repair and maintenance of the cells. Amino acids microbial catabolism produces key flavour compounds in foods such as cheese, wine, honey and other fermented foodstuff [2]. From their enzymatic decarboxylation results the formation of biogenic amines [3], undesirable compounds when in higher levels due to the physiological effects in the human organism, consequence of their toxicology. Biogenic amines are a group of organic bases, namely aliphatic (putrescine and cadaverine),

\footnotetext{
* Corresponding author. Tel.: +351 291705103; fax: +351 291705149 .

E-mail address: marques@uma.pt (J.C. Marques).
}

aromatic (tyramine) and heterocyclic amines (histamine) with low-molecular weight [4]. Consumption of high amounts of these amines, namely histamine, can result in intoxication symptoms such as headache, nausea, rushes, hypo- or hypertension and digestive problems, whereas tyramine and phenylethylamine have been associated with migraines and hypertension [5]. The study of biogenic amines can also be used as an indicator of food quality since their occurrence is normally associated with inadequate sanitary conditions during the production procedures. The determination of the amino acids and biogenic amines is of great importance in food industry due to nutritional labelling requirements, control of process operating conditions and, eventually, in the determination of origin, as used for honey [6] in substitution of mellissopalynology. This method, recommended for the analysis and identification of pollens contained in honey, is extremely tedious, high time-consuming and requires a very skilful analyst for data interpretation [7]. Considering that about $1 \%$ of the non sugar/water fraction of honey is due to amino acids related to animal and vegetal sources, mainly bees and pollen [8], the amino acids profile can be advantageously used for the 
characterization. In a similar way, they can be used for the characterization of wines. Amino acids act as a source of nitrogen (30-40\%) for yeast during alcoholic fermentation, interacting in the aromatic composition of wine and, according to several authors [9-12], their composition may be a suitable method for the classification of wines according to variety, geographical origin, wine-making technologies and vintage.

Biogenic amines, naturally present in grapes and in wines, derive mostly from malolactic fermentation $[13,14]$ from the decarboxylation of free amino acids by the action of lactic acid bacteria. In recent years, new trends in food safety, together with the consumers' demand for quality and healthier products, have encouraged several authors to study these compounds in several wines [4,15-17] while in honeys, and as far as we know, no studies have been published. The most common biogenic amines found in wines are histamine, tyramine, putrescine and phenylethylamine [18].

Diverse analytical methods have been proposed for the analysis of amino acids and biogenic amines including gas chromatography (GC) [19-21], high-performance liquid chromatography (HPLC) [22,23] and capillary electrophoresis (EC) [24,25]. More recently, liquid chromatography coupled with tandem mass spectrometry (LC-MS/MS) has been shown to be a very specific and sensitive technique for the determination of underivatized amino acids [2,26-31], but reported applications of these methods to biological measurements are limited. Besides involving shorter analysis times the LC-MS/MS technique is expensive and is not available in many research laboratories. There are some methods used for the simultaneous determination of amino acids and biogenic amines by HPLC [32-35], micellar electrokinetic capillary chromatography (MECC) [36] and micellar liquid chromatography (MLC) [37]. Traditionally, the determination of amino acids has been conducted by ion-exchange chromatography, followed by post-column derivatization with ninhydrin. So far, the analysis of these compounds using precolumn derivatization and reversed-phase HPLC separation of the derivatives has become widely accepted and usually shows great sensitivity. Typical derivatization reagents include 9-fluorenylmethyl chloroformate (FMOC-Cl) [38,39], $\mathrm{N}$-(9-fluorenylmethoxycarbonyloxy)succinimide (FMOC-OSu) [35], carbazole-9-yl-acetyl chloride (CRA-Cl) [40], orthophthalaldeyde (OPA) [41,42], phenyl isothiocyanate (PITC) [41,43], 1-fluoro-2,4-dinitrophenyl-5-L-alanine amide [44] and dansylchloride $[45,46]$.

This study indented to develop a simple RP-HPLC methodology for the simultaneous identification and quantification of amino acids and biogenic amines in liquid food matrices, based on a pre-column OPA derivatization carried out in the chromatograph injection loop. The OPA/MCE reagent was selected due to its high sensitivity and response to minor amino acids. OPA in the presence of 2-mercaptoethanol (MCE) reacts with amino acids and biogenic amines and proceeds to isoindolic derivatives, at room temperature, in a quick and simple reaction. The secondary amino acids, proline and hydroxyproline, are not determined as they do not react. Some derivatives are unstable making crucial an appropriate control of the reaction and injec- tion time [47]. Furthermore, this derivatization reagent allows the simultaneous analysis of these compounds without extraction and purification processes preceding the derivatization with fluorescent functional group detection $[1,24]$. In order to simplify the derivatization procedure and the reproducibility of the results, this work was focused in the derivatization operating conditions to be accomplished in the sample injection loop. This methodology was applied to honey and wine samples obtained from different production processes and geographic origins.

\section{Experimental}

\subsection{Standards and reagents}

Ultra-pure water was obtained from a Milli Q-System (Millipore, Milford, MA, USA) while HPLC-grade methanol was obtained from Sigma-Aldrich (St. Louis, MO, USA). Tetrahydrofuran (99.5\%), ethanol (99.9\%), sodium hydroxide (98\%), sodium phosphate monobasic monohydrate $(98 \%)$ are from Panreac Quimica SA (Barcelona, Spain). o-Phthaldialdehyde (p.a.), 2-mercaptoethanol (99\%) were supplied by Acros Organics (Geel, Belgium), hydrochloric acid (p.a.) by Riedel-de Haën (Seelze, Germany) and boric acid (99.5\%) by Merck Co. (Darmstadt, Germany)

A kit of high purity L-amino acids (>98\%) was supplied by Sigma-Aldrich (St. Louis, MO, USA) and consisted of $1 \mathrm{~g}$ of each of the following standards: aspartic acid (Asp), glutamic acid (Glu), asparagine (Asn), serine (Ser), glutamine (Gln), histidine (His), glycine (Gly), threonine (Thr), arginine (Arg), alanine (Ala), tyrosine (Tyr), methionine (Met), tryptophan (Trp), valine (Val), phenylalanine (Phe), isoleucine (Ile), leucine (Leu) and lysine (Lys).

The following standards were supplied by Fluka BioChemika AG (Buchs, Switzerland): $\gamma$-aminobutyric acid (GABA) and the biogenic amines: histamine (Him), tyramine (Tym), phenylethylamine (Phm) isopenthylamine (Ism), and cadaverine (Cad). Tryptamine (Trm) was purchased from Acros Organics (Geel, Belgium).

A concentrated $10 \mathrm{~g} / \mathrm{l}$ stock solution of each amino acid and biogenic amine was prepared in $0.1 \mathrm{M} \mathrm{HCl}$. Calibration standards (ranging from 0.5 to $60.0 \mathrm{mg} / \mathrm{l}$ ) were prepared in $0.1 \mathrm{M}$ $\mathrm{HCl}$ from the concentrated standard solution. Finally, they were filtered through a $0.45 \mu \mathrm{m}$ filter (Acrodisc ${ }^{\circledR}$ CR-PTFE, Ann Arbor, SOM, USA), stored in a refrigerator and protected from light.

\subsection{Equipment}

Amino acids and biogenic amines were simultaneously separated in a HPLC system using a Waters (Milford, MA, USA) liquid chromatograph controlled by the Empower Pro software and equipped with an auto-injector (Waters 2695, separations module) and a Multi $\lambda$ Fluorescence detector (Waters 2475). Chromatographic analysis were performed using an analytical scale $(3.9 \mathrm{~mm} \times 150 \mathrm{~mm})$ Nova-Pack RP-C 18 column, with a particle size of $4 \mu \mathrm{m}$, purchased from Waters (Milford, MA, USA). 
Table 1

Gradient program employed for the separation of amino acids and biogenic amines

\begin{tabular}{rlcl}
\hline Time $(\mathrm{min})$ & Flow $(\mathrm{ml} / \mathrm{min})$ & Eluent A $(\%)$ & Curve \\
\hline 0 & 1.00 & 100 & 6 \\
6 & 1.00 & 100 & 6 \\
17 & 1.00 & 85 & 6 \\
25 & 1.00 & 80 & 6 \\
33 & 1.00 & 70 & 6 \\
45 & 1.00 & 60 & 6 \\
61 & 1.00 & 20 & 6 \\
67 & 1.00 & 0 & 6 \\
70 & 1.00 & 0 & 6 \\
71 & 1.00 & 100 & 1 \\
80 & 1.00 & 100 & 6 \\
\hline
\end{tabular}

\subsection{Chromatographic conditions}

HPLC conditions were as follow: mobile phase A: $1 \%$ of tetrahydrofuran, $8 \%$ methanol and $91 \%$ phosphate buffer $(10 \mathrm{mM})$. Mobile phase B: $80 \%$ methanol and $20 \%$ phosphate buffer $(10 \mathrm{mM})$.

The flow rate was set at $1 \mathrm{ml} / \mathrm{min}$ and the column maintained at $35^{\circ} \mathrm{C}$. The eluted OPA derivatives were detected by monitoring their fluorescence at 335 and $440 \mathrm{~nm}$ as excitation and emission wavelengths, respectively. The injections were performed in less than $80 \mathrm{~min}$, including column regeneration and stabilization during the last $13 \mathrm{~min}$. The gradient program used is shown in Table 1.

\subsection{Samples}

A total of 21 samples were analyzed with the developed method (12 honeys and 9 wines-see Table 2). The honey samples include nine multifloral and three monofloral, from different origins namely Madeira islands (H1-H5), Portugal mainland (H6-H8) and Canary islands (H9-H12), purchased in local stores. The wine samples include four Madeira fortified wines (W1-W4), three Madeira table wines (W5-W7) and two Canarian table wines (W8 and W9) from the following grape varieties: Malvasia, Tinta Negra Mole and Sercial.

Before the derivatization procedure, $200 \mu l$ of the sample were added to $1.5 \mathrm{ml}$ of a $0.4 \mathrm{M}$ borate buffer solution $(\mathrm{pH}$ 10.5 ), homogenized in a vortex agitator and then filtered through $0.45 \mu \mathrm{m}$ PTFE filter. In case of honey samples, $5 \mathrm{~g}$ were diluted with ultrapure water into a $10 \mathrm{ml}$ volumetric flask and filtered.

\subsection{Derivatization}

OPA derivatization solution was prepared in a $10 \mathrm{ml}$ volume flask by dissolving $250 \mathrm{mg}$ of reagent in $1.5 \mathrm{ml}$ of ethanol and making up the volume with $0.4 \mathrm{M}$ borate buffer ( $\mathrm{pH} 10.5$ ). Finally $200 \mu \mathrm{l}$ of 2 -mercaptoethanol was added. At last, the reagent solution was left to settle for $90 \mathrm{~min}$, stored in dark glass vials at $4{ }^{\circ} \mathrm{C}$ and freshly prepared every 9 days.

The derivatization procedure was performed in the sample injection loop according to the following sequence: $10 \mu \mathrm{l}$ of
Table 2

Samples analyzed by the developed HPLC method

\begin{tabular}{|c|c|c|}
\hline Samples & Characteristics & Origin \\
\hline \multicolumn{3}{|l|}{ Honey } \\
\hline $\mathrm{H} 1$ & Multifloral & \multirow{5}{*}{ Madeira islands } \\
\hline $\mathrm{H} 2$ & Multifloral & \\
\hline $\mathrm{H} 3$ & Multifloral & \\
\hline $\mathrm{H} 4$ & Multifloral & \\
\hline H5 & Multifloral & \\
\hline H6 & Monofloral & \multirow{3}{*}{ Portugal mainland } \\
\hline $\mathrm{H} 7$ & Multifloral & \\
\hline $\mathrm{H} 8$ & Monofloral & \\
\hline H9 & Multifloral & \multirow[t]{4}{*}{ Canary islands } \\
\hline $\mathrm{H} 10$ & Monofloral & \\
\hline H11 & Multifloral & \\
\hline $\mathrm{H} 12$ & Multifloral & \\
\hline \multicolumn{3}{|l|}{ Wine } \\
\hline \multicolumn{3}{|c|}{ Fortified } \\
\hline W1 & Malvasia (sweet) & \multirow{4}{*}{ Madeira islands } \\
\hline W2 & Sercial (dry) & \\
\hline W3 & Tinta Negra Mole (sweet) & \\
\hline W4 & Tinta Negra Mole (dry) & \\
\hline \multicolumn{3}{|l|}{ Table } \\
\hline W5 & Malvasia & \multirow{3}{*}{ Madeira islands } \\
\hline W6 & Tinta Negra Mole (rosé) & \\
\hline W7 & Tinta Negra Mole (red) & \\
\hline \multicolumn{3}{|l|}{ Table } \\
\hline W8 & Malvasia & \multirow[t]{2}{*}{ Canary islands } \\
\hline W9 & Malvasia & \\
\hline
\end{tabular}

buffered sample mixture were aspired to the injection loop followed by $10 \mu \mathrm{l}$ of OPA solution and maintained for $3 \mathrm{~min}$ to promote the derivatization reaction. During this period, the flow is maintenance at $0 \mathrm{ml} / \mathrm{min}$ to keep the reagent into the loop. Then, the loop content $(20 \mu \mathrm{l})$ was forced to enter into the column by changing the mobile phase flow to $1 \mathrm{ml} / \mathrm{min}$

\subsection{Calculations}

The concentration of each analyte was obtained by direct interpolation of the peak area in the correspondent linear calibration curve (peak area vs. concentration, ranging from 0.5 to $60.0 \mathrm{mg} / \mathrm{l})$. Samples were diluted when needed to comply with the working range.

\section{Results and discussion}

\subsection{Derivatization procedure}

Derivatization of the standard amino acid and biogenic amines mixture was performed by OPA/MCE in boric buffer ( $0.4 \mathrm{M}$ sodium borate, $\mathrm{pH} 10.5$ ). The first experiments were carried out using an injection volume of $50 \mu \mathrm{l}(25 \mu \mathrm{l}$ of buffered sample mixture and $25 \mu 1$ of OPA/MCE reagent) but the volume was reduced in order to extend column life without compromising the good response. 
Table 3

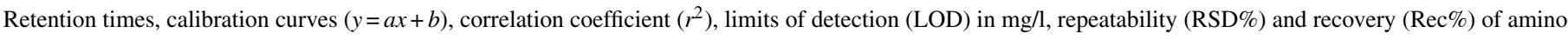
acids and biogenic amines

\begin{tabular}{|c|c|c|c|c|c|c|c|c|}
\hline & Retention times (min) & $a\left(\times 10^{5}\right)$ & $b\left(\times 10^{5}\right)$ & $r^{2}$ & $\mathrm{SD}\left(\times 10^{5}\right)$ & LOD & Rep (RSD\%) & $\operatorname{Rec}(\%)$ \\
\hline \multicolumn{9}{|l|}{ Amino acids } \\
\hline Aspartic acid & $1.33 \pm 0.28$ & 23.30 & 27.40 & 0.998 & 14.68 & 0.71 & 0.60 & 98 \\
\hline Glutamic acid & $2.52 \pm 0.30$ & 21.20 & 13.40 & 0.999 & 14.45 & 1.41 & 1.65 & 91 \\
\hline Asparagine & $8.60 \pm 0.52$ & 19.10 & 6.94 & 0.999 & 11.89 & 1.50 & 1.49 & 90 \\
\hline Serine & $11.10 \pm 0.35$ & 32.00 & 12.30 & 0.998 & 28.69 & 2.30 & 0.14 & 85 \\
\hline Glutamine & $13.74 \pm 0.25$ & 2.29 & 0.58 & 0.994 & 4.07 & 5.08 & 4.14 & 90 \\
\hline Histidine & $14.25 \pm 0.45$ & 9.54 & -3.67 & 0.998 & 8.57 & 2.73 & 1.92 & 90 \\
\hline Glycine & $17.25 \pm 0.38$ & 45.50 & -11.70 & 0.997 & 52.92 & 3.75 & 1.09 & 87 \\
\hline Threonine & $19.15 \pm 0.30$ & 24.10 & 8.92 & 0.999 & 18.73 & 1.96 & 2.55 & 88 \\
\hline Arginine & $21.89 \pm 0.65$ & 17.40 & 1.72 & 0.998 & 15.79 & 2.62 & 0.58 & 85 \\
\hline Alanine & $26.15 \pm 0.25$ & 36.20 & -0.14 & 0.998 & 36.15 & 3.00 & 0.72 & 85 \\
\hline GABA & $28.50 \pm 0.25$ & 30.50 & -22.40 & 0.996 & 42.26 & 4.89 & 0.89 & 83 \\
\hline Tyrosine & $32.50 \pm 0.40$ & 17.60 & 4.87 & 0.999 & 12.14 & 1.79 & 0.51 & 91 \\
\hline Methionine & $45.20 \pm 0.25$ & 21.40 & -0.89 & 0.991 & 45.14 & 6.37 & 7.92 & 98 \\
\hline Tryptophan & $46.25 \pm 0.35$ & 31.20 & 16.70 & 0.999 & 16.98 & 1.10 & 0.39 & 91 \\
\hline Valine & $47.50 \pm 0.20$ & 13.60 & -1.56 & 0.998 & 12.49 & 2.87 & 0.56 & 82 \\
\hline Phenylalanine & $50.20 \pm 0.30$ & 19.10 & 2.21 & 0.999 & 15.97 & 2.39 & 0.63 & 83 \\
\hline Isoleucine & $52.50 \pm 0.45$ & 29.90 & 10.30 & 0.999 & 19.27 & 1.59 & 0.88 & 91 \\
\hline Leucine & $53.90 \pm 0.25$ & 27.30 & 3.42 & 0.999 & 21.30 & 2.21 & 0.67 & 88 \\
\hline Lysine & $59.50 \pm 0.40$ & 6.78 & -8.75 & 0.990 & 15.74 & 8.26 & 5.41 & 82 \\
\hline \multicolumn{9}{|l|}{ Biogenic amines } \\
\hline Histamine & $49.10 \pm 0.45$ & 29.50 & -25.30 & 0.996 & $4,209,260$ & 5.14 & 0.40 & 87 \\
\hline Tyramine & $58.90 \pm 0.25$ & 28.90 & -24.30 & 0.994 & $4,972,310$ & 6.00 & 6.04 & 82 \\
\hline Tryptamine & $63.50 \pm 0.30$ & 21.90 & -25.10 & 0.994 & $3,815,051$ & 6.37 & 0.66 & 81 \\
\hline Phenylethylamine & $64.75 \pm 35$ & 24.20 & -18.10 & 0.995 & $3,963,053$ & 5.66 & 0.24 & 78 \\
\hline Isopenthylamine & $65.80 \pm 0.20$ & 35.00 & 1.75 & 0.994 & $4,184,279$ & 3.54 & 5.14 & 91 \\
\hline Cadaverine & $67.00 \pm 0.20$ & 20.50 & -19.80 & 0.992 & $4,182,516$ & 7.09 & 1.09 & 63 \\
\hline
\end{tabular}

Most part of published methods requires sample pretreatment before derivatization [6,48,49]. Paramás et al. [48] developed an OPA/MCE derivatization method for the determination of amino acids in honey that includes a clean-up step and an extraction procedure before derivatization. The developed method has the advantage of a simpler methodology, not requiring any complex pre-treatment for liquid food matrices and only a dilution is carried out, if necessary. OPA-derivatization times are short ( $3 \mathrm{~min}$ ) when compared when other derivatization reagents are used for the simultaneous determination of these compounds $[32,33,35]$. The proposed method by Bauza et al. [33] using FMOC as derivatization reagent needs 6 min for reaction development, while Krause et al. [32] used a dabsyl method and the derivatization time was $20 \mathrm{~min}$. Lately, Lozanov et al. [35] proposed the use of FMOC-OSu reacting during 20 min. OPA derivatization does not show the presence of excess reagent, interfering with the analytes resolution, as detected when using FMOC derivatization methods [35]. Furthermore, the derivatization reaction is automatic, occurs in the injection loop and shows sensitive and consistent results.

\subsection{Method validation}

The sample analytes were identified by comparison with the retention times of amino acid standard solutions. For the determination of retention times, the reference standards were injected both individually and as a mixture. Quantification was performed by the external standard method based on peak areas of the eluted amino acid and biogenic amines derivatives.

The linearity was evaluated by the construction of calibration curves, using the chromatographic peaks areas of the fluorescence response from triplicate injections of standards, at six increasing concentrations in the $0.5-60.0 \mathrm{mg} / \mathrm{l}$ range for all amino acids and biogenic amines. The linear relationship between concentrations and peak area is given by $a, b$ and $r^{2}$-see Table 3, where $a$ and $b$ are the coefficients of the regression equation $y=a x+b, x$ being the concentration of the analyte, $y$ the peak area and $r^{2}$ the coefficient of determination. For this calculation, all obtained values were used instead the average of the three injections. In all cases, the relationship between concentrations and peak areas were linear over the tested range, with coefficients of determination greater than 0.990 . The repeatability of the method was evaluated by nine consecutive injections of the same sample during a working day. Detection limits (defined as three times the signal-to-noise ratio) ranged from $0.71 \mathrm{mg} / \mathrm{l}$ (Asp) to $8.26 \mathrm{mg} / \mathrm{l}$ (Lys)-Table 3.

To determine intra-sample and inter-day precisions for the analyses of amino acids and biogenic amines in honeys and wines, three identical samples were run on three separate days. Intra-samples precisions for individual measurements of amino acids range from 1.9 to $4.8 \%$ and the inter-day precisions range from 4.2 to $9.4 \%$ (RSD). Biogenic amines were not considered as only vestigial quantities were found. The calculated concentrations of individual amino acids showed residual standard 

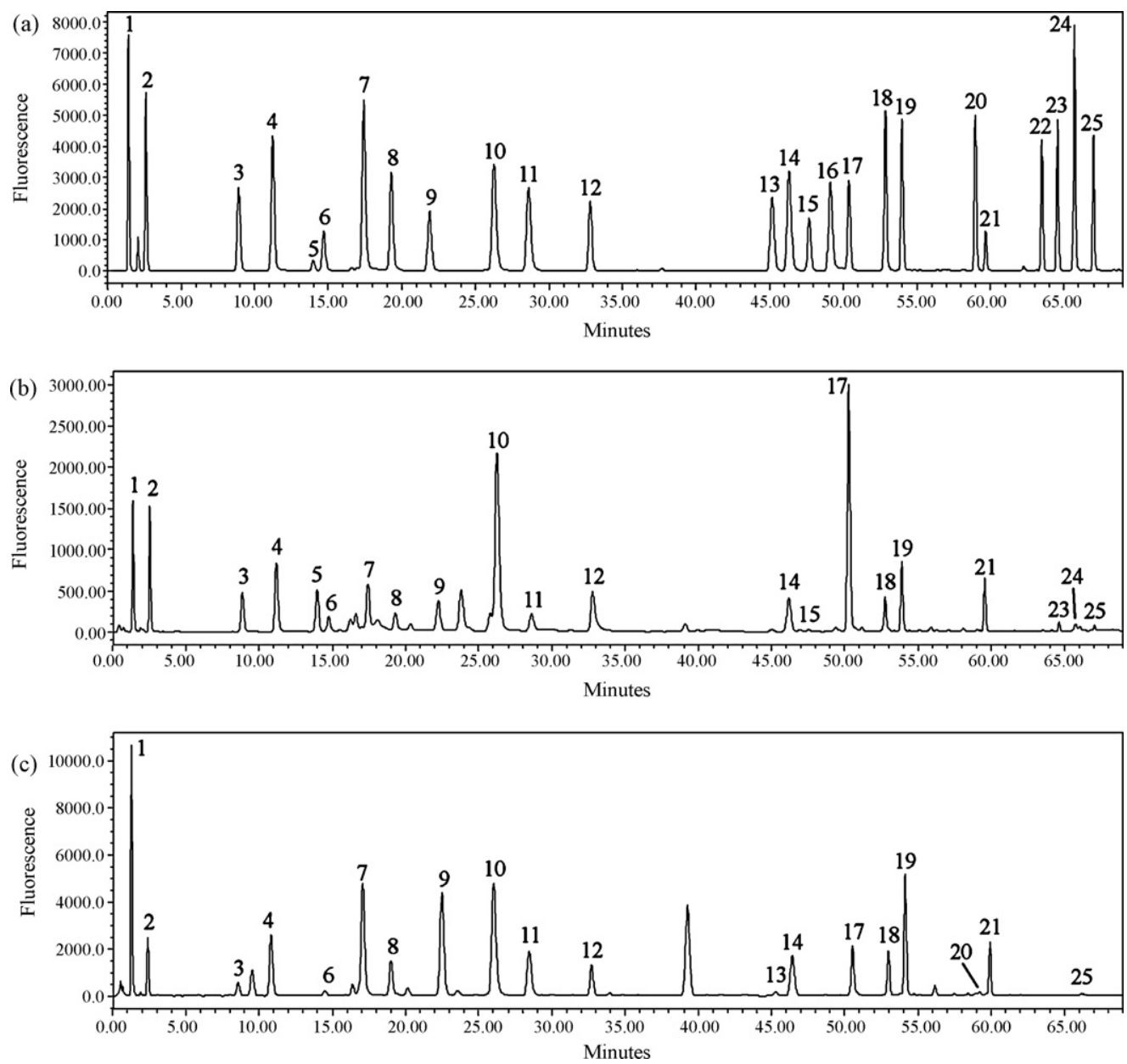

Fig. 1. Typical chromatogram profile of amino acids and biogenic amines in: (a) $20 \mathrm{mg} / \mathrm{l}$ standard mixture, (b) H5 honey and (c) W4 wine. Peak identification: (1) aspartic acid, (2) glutamic acid, (3) asparagine, (4) serine, (5) glutamine, (6) histidine, (7) glycine, (8) threonine, (9) arginine, (10) alanine, (11) GABA, (12) tyrosine, (13) methionine, (14) tryptophan, (15) valine, (16) histamine, (17) phenylalanine, (18) isoleucine, (19) leucine, (20) tyramine, (21) lysine, (22) tryptamine, (23) phenylethylamine, (24) isopenthylamine and (25) cadaverine.

deviations (RSD) of about $2 \%$ in the analyses of wine and honey samples.

The accuracy was estimated by means of the recovery tests. For the evaluation of the recovery rate, H3 honey and W7 wine $(n=5)$ were spiked with $10 \mathrm{mg} / \mathrm{l}$ standard solution, derivatizated and quantified. The recovery rate averages obtained were acceptable, with values ranging from $82 \%$ (Lys) to $98 \%$ (Asp) for amino acids, and $63 \%$ (Cad) to $91 \%$ (Ism) for biogenic amines-Table 3 .

\subsection{Chromatographic analysis}

The proposed HPLC method allows the simultaneous determination of 19 amino acids and 6 biogenic amines in $83 \mathrm{~min}$, including the column regeneration $(9 \mathrm{~min})$ and derivatization time (3 min), slightly higher than the methodology suggested by Alberto et al. [34], $63 \mathrm{~min}$, but ensuring better separation. The applied methodology allows the total separation of all amino acids and biogenic amines in the standards solutions and analysed matrices, overcoming some peak overlay obtained by several authors [8,50-52] namely Asn + Ser [50,8], Gln + Thr [50], Asp + Asn [51], Glu + Gln [51] and Thr + Ala [52]. Fig. 1 shows the separation obtained for the amino acids and biogenic amines present in a $20 \mathrm{mg} / \mathrm{l}$ standard solution, together with typical chromatograms obtained for honey (H5) and wine (W4).

More than the determination of amino acid composition, this methodology is a useful tool for the control of biogenic amines with known toxic activity, like phenylethylamine, histamine (maximum recommended levels of 5-6 mg/l in Belgium

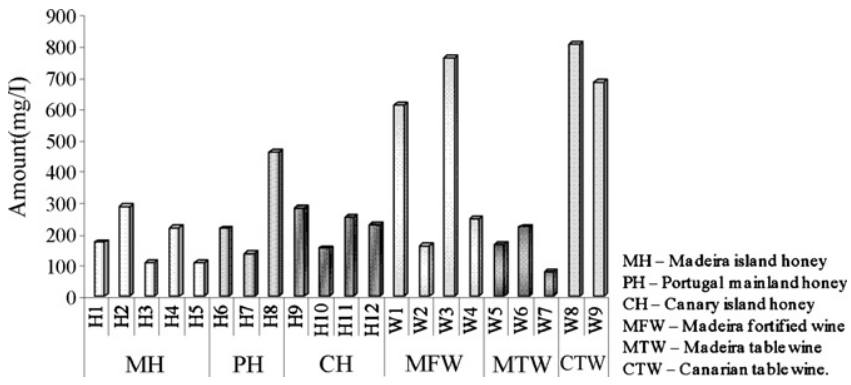

Fig. 2. Amount of amino acid in the liquid food matrices studied. MH, Madeira islands honey; PH, Portugal mainland honey; $\mathrm{CH}$, Canary islands honey; $\mathrm{MFW}$, Madeira fortified wine; MTW, Madeira table wine; CTW, Canarian table wine. 
Table 4

$\underline{\text { Levels }(\mathrm{mg} / \mathrm{l}) \text { of free amino acids in studied honey and wine samples with the respective standard deviation of the mean value }(n=3 \text { for each data point) }}$

\begin{tabular}{|c|c|c|c|c|c|c|c|c|c|c|c|c|c|c|c|c|c|c|c|}
\hline & Asp & $\begin{array}{c}\text { Glu } \\
\end{array}$ & Asn & Ser & Gln & His & Gly & $\begin{array}{l}\text { Thr } \\
\end{array}$ & $\operatorname{Arg}$ & Ala & GABA & Tyr & Met & Trp & $\begin{array}{l}\text { Val } \\
\end{array}$ & Phe & Ile & Leu & Lys \\
\hline \multirow{2}{*}{\multicolumn{20}{|c|}{$\begin{array}{l}\text { Honeys } \\
\text { Madeira island }\end{array}$}} \\
\hline & & & & & & & & & & & & & & & & & & & \\
\hline H1 & $3.73 \pm 0.080$ & $4.65 \pm 0.11$ & $2.83 \pm 0.01$ & $<$ LOD & $39.99 \pm 0.30$ & $3.20 \pm 0.20$ & $<\mathrm{LOD}$ & $<\mathrm{LOD}$ & $3.36 \pm 0.03$ & $3.69 \pm 0.04$ & $<\mathrm{LOD}$ & $4.77 \pm 0.35$ & n.d. & $3.31 \pm 0.00$ & $<\mathrm{LOD}$ & $76.38 \pm 0.72$ & $2.24 \pm 0.02$ & $10.74 \pm 0.12$ & $12.58 \pm 0.83$ \\
\hline $\mathrm{H} 2$ & $3.89 \pm 0.01$ & $5.64 \pm 0.01$ & $2.85 \pm 0.03$ & $2.67 \pm 0.00$ & $55.19 \pm 0.48$ & $4.71 \pm 0.00$ & $<\mathrm{LOD}$ & $<$ LOD & $2.99 \pm 0.00$ & $7.77 \pm 0.01$ & $<\mathrm{LOD}$ & $8.44 \pm 0.02$ & n.d. & $5.56 \pm 0.00$ & $<\mathrm{LOD}$ & $146.65 \pm 1.65$ & $4.07 \pm 0.01$ & $23.09 \pm 0.02$ & $12.48 \pm 0.12$ \\
\hline $\mathrm{H} 3$ & $3.33 \pm 0.04$ & $4.94 \pm 0.04$ & $3.01 \pm 0.00$ & $3.44 \pm 0.03$ & $32.71 \pm 0.37$ & $2.73 \pm 0.18$ & $<\mathrm{LOD}$ & $<$ LOD & $3.61 \pm 0.03$ & $12.41 \pm 0.05$ & $<\mathrm{LOD}$ & $5.47 \pm 0.01$ & $\mathrm{nd}$. & $2.03 \pm 0.01$ & n.d. & $19.99 \pm 0.02$ & $<\mathrm{LOD}$ & $3.24 \pm 0.00$ & $9.75 \pm 0.08$ \\
\hline $\mathrm{H} 4$ & $6.26 \pm 0.27$ & $11.77 \pm 0.27$ & $3.29 \pm 0.00$ & $4.77 \pm 0.11$ & $34.06 \pm 0.86$ & $6.73 \pm 0.21$ & $<$ LOD & $3.21 \pm 0.04$ & $<$ LOD & $6.41 \pm 0.05$ & $<$ LOD & $20.65 \pm 0.28$ & n.d & $3.37 \pm 0.00$ & $6.45 \pm 0.00$ & $97.76 \pm 0.08$ & $2.36 \pm 0.01$ & $1.79 \pm 0.01$ & $9.43 \pm 0.06$ \\
\hline H5 & $3.54 \pm 0.04$ & $6.36 \pm 0.01$ & $5.51 \pm 0.05$ & $2.73 \pm 0.00$ & $32.56 \pm 0.22$ & $5.07 \pm 0.00$ & $<\mathrm{LOD}$ & $<\mathrm{LOD}$ & $3.67 \pm 0.00$ & $4.45 \pm 0.09$ & $<$ LOD & $6.49 \pm 0.02$ & n.d. & $2.45 \pm 0.01$ & $<\mathrm{LOD}$ & $20.37 \pm 0.06$ & $<\mathrm{LOD}$ & $<$ LOD & $12.63 \pm 0.16$ \\
\hline \multicolumn{20}{|c|}{ Portugaal mainland } \\
\hline $\mathrm{H} 6$ & $3.82 \pm 0.04$ & $2.84 \pm 0.06$ & $4.95 \pm 0.05$ & $3.56 \pm 0.01$ & $20.08 \pm 0.11$ & $4.77 \pm 0.05$ & $<$ LOD & $<$ LOD & $4.27 \pm 0.15$ & $3.72 \pm 0.08$ & $<$ LOD & $33.84 \pm 0.35$ & n.d. & $1.65 \pm 0.05$ & $<\mathrm{LOD}$ & $109.61 \pm 0.29$ & $1.62 \pm 0.02$ & $11.11 \pm 0.12$ & $8.71 \pm 0.12$ \\
\hline $\mathrm{H} 7$ & $5.49 \pm 0.13$ & $6.58 \pm 0.14$ & $3.81 \pm 0.10$ & $3.33 \pm 0.09$ & $26.93 \pm 1.19$ & $4.92 \pm 0.03$ & $<\mathrm{LOD}$ & $<\mathrm{LOD}$ & $4.00 \pm 0.03$ & $8.02 \pm 0.01$ & $<\mathrm{LOD}$ & $8.91 \pm 0.14$ & n.d & $2.37 \pm 0.00$ & $<\mathrm{LOD}$ & $47.69 \pm 0.39$ & $<\mathrm{LOD}$ & $2.32 \pm 0.02$ & $9.49 \pm 0.03$ \\
\hline H8 & $23.65 \pm 0.28$ & $39.23 \pm 0.45$ & $15.17 \pm 0.89$ & $7.76 \pm 0.53$ & $154.42 \pm 0.91$ & $4.07 \pm 1.36$ & $4.15 \pm 0.18$ & $3.26 \pm 0.16$ & $9.98 \pm 0.26$ & $11.36 \pm 0.29$ & $8.70 \pm 0.17$ & $9.07 \pm 0.06$ & n.d & $6.79 \pm 0.07$ & $<\mathrm{LOD}$ & $145.28 \pm 1.53$ & $3.70 \pm 0.02$ & $3.02 \pm 0.00$ & $8.42 \pm 0.09$ \\
\hline \multicolumn{20}{|c|}{ Canary island } \\
\hline $\mathrm{H} 9$ & $2.29 \pm 0.10$ & $4.74 \pm 0.04$ & $2.66 \pm 0.04$ & $3.19 \pm 0.03$ & $31.34 \pm 0.06$ & $6.21 \pm 0.07$ & $<\mathrm{LOD}$ & $<\mathrm{LOD}$ & $3.43 \pm 0.05$ & $3.58 \pm 0.00$ & $<\mathrm{LOD}$ & $40.67 \pm 0.01$ & n.d. & $2.06 \pm 0.02$ & $<$ LOD & $159.68 \pm 0.17$ & $<\mathrm{LOD}$ & $3.85 \pm 0.01$ & $15.62 \pm 0.00$ \\
\hline $\mathrm{H} 10$ & $17.04 \pm 0.39$ & $9.28 \pm 0.27$ & $17.93 \pm 0.36$ & $3.85 \pm 0.03$ & $57.08 \pm 1.26$ & $5.77 \pm 0.05$ & $<\mathrm{LOD}$ & $<\mathrm{LOD}$ & $4.58 \pm 0.03$ & $5.24 \pm 0.02$ & $<\mathrm{LOD}$ & $6.10 \pm 0.05$ & n.d. & $3.44 \pm 0.04$ & n.d. & $10.44 \pm 0.05$ & $1.85 \pm 0.02$ & $<$ LOD & $8.85 \pm 0.12$ \\
\hline H11 & $43.85 \pm 0.91$ & $45.58 \pm 0.47$ & $4.42 \pm 0.26$ & $7.36 \pm 0.82$ & $91.68 \pm 2.74$ & $3.05 \pm 0.20$ & $8.42 \pm 0.03$ & $<\mathrm{LOD}$ & $<\mathrm{LOD}$ & $19.99 \pm 0.06$ & $<\mathrm{LOD}$ & $2.64 \pm 0.18$ & n.d. & $5.21 \pm 0.09$ & n.d. & $15.74 \pm 0.36$ & $<\mathrm{LOD}$ & $3.89 \pm 0.00$ & $<\mathrm{LOD}$ \\
\hline H12 & $6.84 \pm 0.06$ & $7.48 \pm 0.06$ & $7.63 \pm 0.54$ & $3.83 \pm 0.09$ & $61.35 \pm 1.41$ & $9.64 \pm 0.38$ & $<$ LOD & $2.62 \pm 0.07$ & $<$ LOD & $5.29 \pm 0.15$ & $<$ LOD & $19.66 \pm 0.13$ & n.d. & $3.58 \pm 0.04$ & $<$ LOD & $74.62 \pm 1.84$ & $2.09 \pm 0.08$ & $<$ LOD & $21.11 \pm 0.24$ \\
\hline
\end{tabular}

Wine

Madeira fortified

$\begin{array}{lllllllllllllll}\text { W1 } & 14.62 \pm 0.08 & 12.16 \pm 0.10 & 2.32 \pm 0.04 & 21.23 \pm 0.09<\mathrm{LOD} & 4.38 \pm 0.09 & 14.03 \pm 0.10 & 19.39 \pm 0.60 & 313.46 \pm 1.62 & 85.74 \pm 0.22 & 95.60 \pm 1.16 & 5.69 \pm 0.04 & <\mathrm{LOD} & 10.61 \pm 0.00 & \text { n.d. }\end{array}$

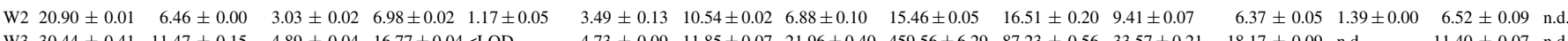

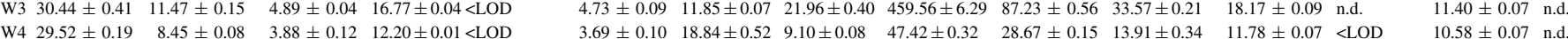

$8.51 \pm 0.02 \quad 3.49 \pm 0.12 \quad 8.33 \pm 0.02 \quad<\mathrm{LOD}$ $9.83 \pm 0.19 \quad 4.81 \pm 0.09 \quad 13.56 \pm 0.32 \quad 15.43 \pm 0.45$ $\begin{array}{lllll}9.33 & \pm 0.07 & 6.72 \pm 0.02 & 13.56 \pm 0.32 & 15.43 \pm 0.45\end{array}$ Madeira table

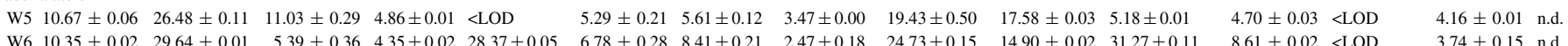

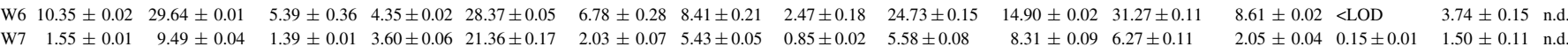

$6.64 \pm 0.03 \quad 3.17 \pm 0.01 \quad 11.00 \pm 0.02 \quad 19.86 \pm 0.09$ $\begin{array}{llll}7.13 \pm 0.05 & 2.35 \pm 0.03 & 9.13 \pm 0.01 & 20.11 \pm 0.14\end{array}$

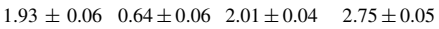

\section{Canarian table}

$\begin{array}{llllllllllllllll}W 8 & 30.13 \pm 0.62 & 46.52 \pm 0.62 & 3.20 \pm 0.10 & 12.09 \pm 0.14<\text { LOD } \quad 84.26 \pm 0.71 & 25.14 \pm 0.32 & 11.69 \pm 0.02 & 278.09 \pm 6.29 & 66.12 \pm 0.67 & 101.65 \pm 3.55 & 29.83 & \pm 0.20 & 6.51 \pm 0.04 & 23.45 & \pm 0.07 & \text { n.d. }\end{array}$

$\begin{array}{lll}7.90 \pm 0.62 & 7.92 \pm 0.02 \quad 22.18 \pm 0.09 & 34.38 \pm 0.29\end{array}$ $\begin{array}{llllllllllllllll}\text { W9 } 37.17 \pm 0.56 & 53.21 \pm 1.01 & 4.42 \pm 0.30 & 12.65 \pm 0.066 .18 \pm 0.56 & 71.18 \pm 0.44 & 25.80 \pm 2.06 & 10.24 \pm 0.61 & 181.55 \pm 1.16 & 48.28 \pm 1.08 & 98.85 \pm 1.26 & 25.92 \pm 0.38 & 6.99 \pm 0.00 & 13.44 \pm 0.26 & <\mathrm{LOD}\end{array}$ 
and $10 \mathrm{mg} / \mathrm{l}$ in Switzerland [53]) and tyramine, considered toxic to human health $(25-40 \mathrm{mg} / \mathrm{l})$ [54].

The results obtained for the honey and wine samples are summarized in Table 4, where only amino acid concentrations are shown as biogenic amines were found only in vestigial quantities, usually below the LOD. The main amino acids found in honey samples were phenylalanine, glutamine and lysine and in wines were arginine, alanine and GABA. Methionine showed very low level in wines and was not detected in honeys.

The total amount of the primary amino acids found is described in Fig. 2. The values range from $76.89 \mathrm{mg} / \mathrm{l}$ (W7) to
$802.40 \mathrm{mg} / \mathrm{l}$ (W8). From the analyzed honeys, Madeira multifloral honey (H2) presents the highest amount of amino acid found, $286.00 \mathrm{mg} / \mathrm{l}$. Analysing Madeira wines from similar grape varieties, it was observed that fermented ones show lower values (about $172.94 \mathrm{mg} / \mathrm{l}$ ) than the wines submitted to partial fermentation, like sweet wines $(684.73 \mathrm{mg} / \mathrm{l}$ in average for W1 and W3), as expected since amino acids are catabolised in several reactions during this step. Comparing the results obtained for the same variety submitted to a different fermentation process (W3 and W4), the content of the following acids decrease at least $50 \%$ during fermentation: arginine, alanine, $\gamma$-aminobutyric acid and

Table 5

Relative abundance $(\%)$ of each amino acid in honeys and wines under study

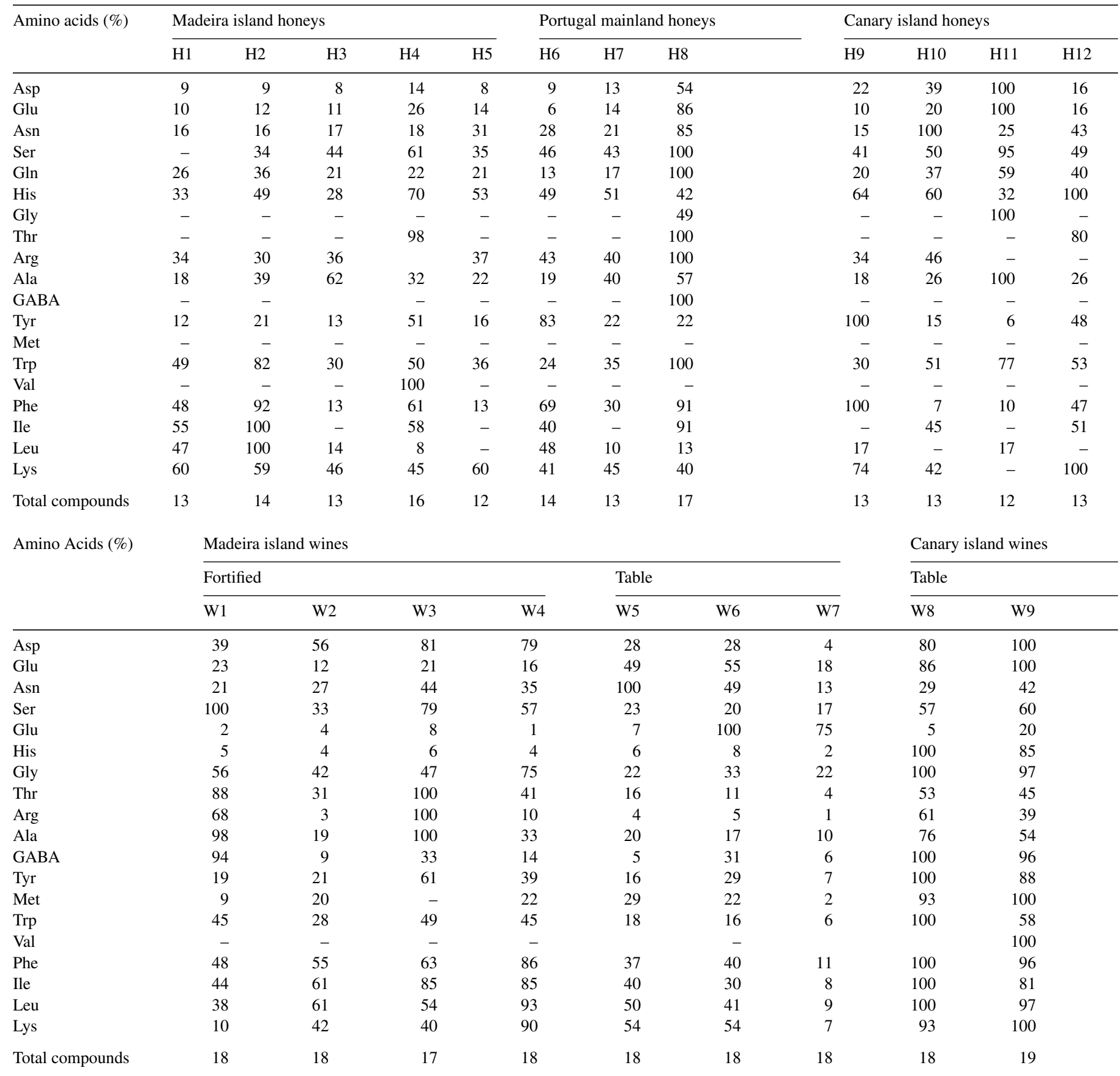


threonine, showing the importance of these amino acids in the formation of typical aromas present in Madeira wines (together with cisteine, not determined with this method, due to low sensitivity). The total amino acid content in Madeira fortified dry wines is similar to Madeira table wines, since the fermentation is almost complete. Canarian table wines present high levels of these compounds ( $741.64 \mathrm{mg} / \mathrm{l}$ in average) close to Madeira submitted to partial fermentation, explained by the fact that those wines were produced from over-maturated Malvasia grapes.

The percentage of the amino acid relative abundance is exposed in Table 5. The samples with the highest relative abundance of amino acids were H8 (honey) due to serine, glutamine, threonine, arginine, GABA and tryptophan and W8 (wine) due to histidine, glycine, GABA, tyrosine, tryptophan, phenylalanine, isoleucine and leucine. Wines besides having higher amounts of amino acids also possess the richest amino acids profile.

The applicability of the reported procedure for simultaneously analysis of amino acids and biogenic amines has been demonstrated for the analysis of honey and wine samples. The reported method is routinely used in our laboratory.

\section{Conclusions}

A simple RP-HPLC analytical method for the simultaneous analysis of amino acids and biogenic amines in liquid food matrices is proposed based on a pre-column derivatization with OPA, performed in the sample injection loop, and fluorescence detection. The separation and quantification of 19 amino acids and nine amines was carried out in a single run as their OPA/MCE derivatives elute within $80 \mathrm{~min}$, ensuring a reproducible quantification. The practical utility of the proposed chromatographic procedure was shown by the analysis of the amino acid and biogenic amine content in honey and wine samples without any preliminary separation or clean-up steps. The method showed high sensitivity and response to minor compounds with the exception to proline, cysteine and hydroxyproline. Future trends pass through the use of shorter columns, to reduce analysis and the application of this procedure to others food matrices.

Relatively to the analysed samples, the amino acid present at the highest concentration in honeys was phenylalanine and in wines was arginine. The biogenic amines suspected to cause toxicological effects (histamine, tyramine and phenylethylamine) were no cause for concern in the analysed honey and wine samples since they are present in vestigial quantities.

\section{Acknowledgments}

Vanda Pereira thanks to Fundação para a Ciência e Tecnologia for the PhD grant SFRH/BD/24177/2005.

This work was financed under project ANTIVINMAC (05/MAC/2.3/M28) from the program INTERREG-IIIB/ FEDER.

\section{References}

[1] D. Kutlán, I. Molnár-Perl, J. Chromatogr. A 987 (2003) 311.
[2] S. Özcan, H. Senyuva, J. Chromatogr. A 1135 (2006) 179.

[3] M.C. Vidal-Carou, R. Codony-Salcedo, A. Mariné-Font, Am. J. Enol. Viticult. 42 (1991) 145.

[4] I. Mafra, P. Herbert, L. Santos, P. Barros, A. Alves, Am. J. Enol. Viticult. 50 (1999) 128.

[5] M.H. Silla-Santos, Int. J. Food Microbiol. 29 (1996) 213.

[6] M.T. Iglesias, C. Lorenzo, M.C. Polo, P.J. Martín-Álvarez, E. Pueyo, J. Agric. Food Chem. 52 (2004) 84

[7] F. Bianchi, M. Careri, M. Musci, Food Chem. 89 (2005) 527.

[8] I. Hermosín, R.M. Chicón, M.D. Cabezudo, Food Chem. 83 (2003) 263

[9] A.M.P. Vasconcelos, H.J. Chaves das Neves, J. Agric. Food Chem. 37 (1989) 931.

[10] G. Noudaje, N. Siméon, F. Dedieu, M. Nertz, F. Ph Puig, Couderc, J. Chromatogr. A 765 (1997) 337.

[11] E.H. Soufleros, M.L. Barrios, A. Bertrand, Am. J. Enol. Viticult. 49 (1998) 266.

[12] E.H. Soufleros, E. Bouloumpasi, C. Tsarchopoulos, C.G. Biliaderis, Food Chem. 80 (2003) 261.

[13] T. Bauza, A. Blaise, J.P. Mestres, P.L. Teissedre, F. Daumas, J.C. Cabanis, Sci. Aliment. 15 (1995) 367.

[14] M.C. Vidal-Carou, A. Ambatlle-Espunyes, M.C. Ulla-Ulla, A. MarinéFont, Am. J. Enol. Viticult. 41 (1990) 160.

[15] M.B. Vazquez-Lasa, M. Iniguez-Crespo, M. Gonzalez-Larraina, A. Gonzalez-Guerrero, Am. J. Enol. Viticult. 49 (1998) 229.

[16] M. Gloria, B. Watson, L. Simon-Sarkadi, M. Daeschel, Am. J. Enol. Viticult. 49 (1998) 279.

[17] P. Herbert, L. Santos, A. Alves, J. Food Sci. 66 (2001) 1319

[18] E. Coton, S. Torlois, A. Bertrand, A. Lonvaud-Funel, Bull. L'OIV 72 (1999) 22 ;

J.M. Alcaide-Hidalgoa, M.V. Moreno-Arribasa, P.J. Martín-Álvareza, M.C. Polo, Food Chem. 103 (2007) 572.

[19] S. Yamamoto, H. Itano, H. Kataoka, M. Makita, J. Agric. Food Chem. 30 (1982) 435.

[20] A. Bandichau, D. Bruyer, R. Ontiveros, W. Shermer, J. Sci. Food Agric. 38 (1987) 1.

[21] M.J. Nozal, J.L. Bernal, M.L. Toribio, J.C. Diego, A. Ruiz, J. Chromatogr A 1047 (2004) 137

[22] J. López-Cervantes, D.I. Sánchez-Machado, J.A. Rosas-Rodrígues, J. Chromatogr. A 1105 (2006) 106.

[23] L. Pripris-Nicolau, G. Revel, S. Marchand, A.A. Beloqui, A. Bertrand, J. Sci. Food Agric. 81 (2001) 731.

[24] C. Bjergegaard, L.P. Hansen, P. Møller, H. Sørensen, S. Sørensen, J. Chromatogr. A 836 (1999) 137.

[25] Á. Kovács, L. Simon-Sarkadi, K. Ganzler, J. Chromatogr. A 836 (1999) 305.

[26] P. Chaimbault, K. Petritis, C. Elfakir, M. Dreux, J. Chromatogr. A 855 (1999) 191.

[27] K. Petritis, P. Chaimbault, C. Elfakir, M. Dreux, J. Chromatogr. A 896 (2000) 253.

[28] J. Qu, Y. Wang, G. Luo, Z. Wu, Yang.F C., Anal. Chem. 74 (2002) 2034.

[29] K. Petritis, C. Elfakir, M. Dreux, J. Chromatogr. A 961 (2002) 9.

[30] J.J. Dalluge, S. Smith, F. Sanchez-Riera, C. McGuire, R. Hobson, J. Chromatog. A 1043 (2004) 3.

[31] A.N. Fonteh, R.J. Harrington, M.G. Harrington, Amino Acids 32 (2007) 203.

[32] I. Krause, A. Bockhardt, H. Neckermann, T. Henle, H. Klostermeyer, J. Chromatogr. A 715 (1995) 67

[33] T. Bauza, A. Blake, F. Daumasb, J.C. Cabanis, J. Chromatogr. A 707 (1995) 373.

[34] M.R. Alberto, M.E. Arena, M.C.M. Nadra, Food Control 13 (2002) 125.

[35] V. Lozanov, S. Petrov, V. Mitev, J. Chromatogr. A 1025 (2004) 201.

[36] Q. Wanga, H. Yua, H. Lib, F. Dinga, P. Hea, Y. Fanga, Food Chem. 83 (2003) 311

[37] M. Gil-Agustí, S. Carda-Broch, L. Monferrer-Pons, J. Esteve-Romero, J. Chromatogr. A 1156 (2007) 288. 
[38] E.M. Sanders, C.S. Ough, Am. J. Enol. Viticult. 36 (1985) 43.

[39] S. Einarsson, J. Chromatogr. 348 (1985) 213.

[40] J. You, H. Sunb, W. Lao, Q. Ou, Anal. Chim. Acta 382 (1999) 51.

[41] B.H. Klein, J.W. Dudenhausen, J. Liq. Chromatogr. 18 (1995) 4007.

[42] P. Lehtonen, Am. J. Enol. Viticult. 47 (1996) 127.

[43] B.A. Bidlingmeyer, S.A. Cohen, T.L. Tarvin, J. Chromatogr. 336 (1984) 93.

[44] J. González-Castro, J. López-Hernández, J. Simal-Lozano, Oruña-Concha, J. Chromatogr. Sci. 35 (1997) 181

[45] P. Fürst, L. Pollack, T.A. Graser, H. Godel, P. Stehle, J. Chromatogr. 449 (1990) 557.

[46] P. Martin, P.A. Suárez, C. Polo, M.D. Cabezudo, M.V. Dabrio, Anal. Bromatol. 32 (1980) 289.
[47] R. Hanczkó, I. Molnár-Perl, Chromatographia 57 (2003) S103.

[48] A.M.G. Paramás, J.A.G. Bárez, C.C. Marcos, R.J. García-Vilanova, J.S. Sánchez, Food Chem. 95 (2006) 148.

[49] O. Busto, J. Guasch, F. Borrull, J. Chromatogr. A 718 (1995) 309.

[50] A.M.C. Davies, R.G. Harris, J. Apicult. Res. 21 (1982) 168.

[51] L.S. Conte, M. Miorini, A. Giomo, G. Bertacco, R. Zironi, J. Agric. Food Chem. 46 (1998) 1844.

[52] P.M. Cometto, P.F. Faye, R.P. Naranjo, M.A. Rubio, M.A.J. Aldao, J. Agric. Food Chem. 51 (2003) 5079.

[53] P. Lehtonen, M. Saarinen, M. Vesanto, M.L. Riekkola, Z. Lebensm. Unters. Forsch. 194 (1992) 434

[54] T. Bauza, A. Blaise, J.P. Mestres, P.L. Teissedre, F. Daumas, J.C. Cabanis, G. Kanny, A. Moneret-Vautrin, Bull. L'OIV 68 (1995) 42. 